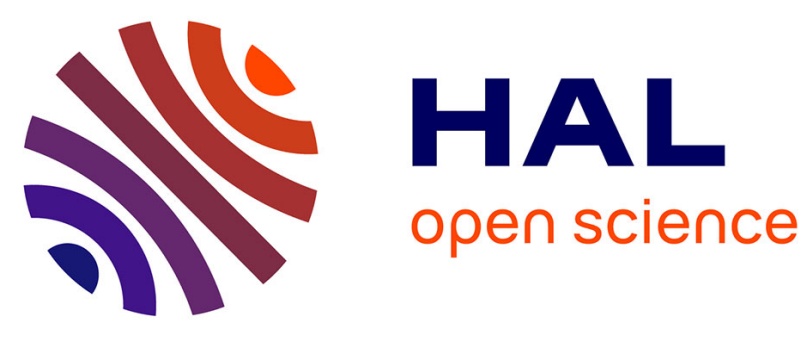

\title{
The Evolution of Electrospray Generated Droplets is Not Affected by Ionization Mode
}

\author{
Piia Liigand, Agnes Heering, Karl Kaupmees, Ivo Leito, Marion Girod, \\ Rodolphe Antoine, Anneli Kruve
}

\section{- To cite this version:}

Piia Liigand, Agnes Heering, Karl Kaupmees, Ivo Leito, Marion Girod, et al.. The Evolution of Electrospray Generated Droplets is Not Affected by Ionization Mode. Journal of The American Society for Mass Spectrometry, 2017, 28 (10), pp.2124 - 2131. 10.1007/s13361-017-1737-5 . hal-01598111

\section{HAL Id: hal-01598111 \\ https://hal.science/hal-01598111}

Submitted on 1 Nov 2020

HAL is a multi-disciplinary open access archive for the deposit and dissemination of scientific research documents, whether they are published or not. The documents may come from teaching and research institutions in France or abroad, or from public or private research centers.
L'archive ouverte pluridisciplinaire HAL, est destinée au dépôt et à la diffusion de documents scientifiques de niveau recherche, publiés ou non, émanant des établissements d'enseignement et de recherche français ou étrangers, des laboratoires publics ou privés. 


\title{
The evolution of electrospray generated droplets is not affected by ionization mode
}

Piia Liigand ${ }^{1}$, Agnes Heering (Suu) ${ }^{1}$, Karl Kaupmees ${ }^{1}$, Ivo Leito ${ }^{1}$, Marion Girod ${ }^{2}$, Rodolphe Antoine $^{3}$, Anneli Kruve ${ }^{1,4}$

${ }^{1}$ Institute of Chemistry, University of Tartu, Ravila 14a, 50411, Tartu, Estonia

${ }^{2}$ Univ Lyon, CNRS, Université Claude Bernard Lyon 1, Ens de Lyon, Institut des Sciences Analytiques, UMR 5280, 5 rue de la Doua, F-69100 Villeurbanne, France

${ }^{3}$ Univ Lyon, Université Claude Bernard Lyon 1, CNRS, Institut Lumière Matière, UMR 5306 F69622, LYON, France

${ }^{4}$ Schulich Faculty of Chemistry, Technion - Israel Institute of Technology, Technion City, Haifa 3200008, Israel

piia.liigand@ut.ee

\begin{abstract}
Ionization efficiency and mechanism in ESI is strongly affected by the properties of mobile phase. The use of mobile phase properties to accurately describe droplets in ESI source is convenient but may be inadequate as the composition of the droplets is changing in the plume due to electrochemical reactions occurring in the needle tip as well as continuous drying and fission of droplets. Presently, there is paucity of research on the effect of the polarity of the ESI mode on mobile phase composition in the droplets. In this paper the change in the organic solvent content, $\mathrm{pH}$ and droplet size are studied in the ESI plume in both ESI+ and ESI- ionization mode. We
\end{abstract}


introduce a rigorous way - the absolute $\mathrm{pH}\left(\mathrm{pH}_{\mathrm{abs}}^{\mathrm{H}_{2} \mathrm{O}}\right)$ - to describe $\mathrm{pH}$ change in the plume that takes into account organic solvent content in the mobile phase. $\mathrm{pH}_{\mathrm{abs}}^{\mathrm{H}_{2} \mathrm{O}}$ enables comparing acidities of ESI droplets with different organic solvent contents. The results are surprisingly similar for both ionization modes indicating that the dynamics of the change of mobile phase properties is independent from the ESI mode used. This allows us to conclude, that the evolution of ESI droplets first of all proceeds via the evaporation of the organic modifier and to a lesser extent via fission of smaller droplets from parent droplets. Secondly, our study shows that qualitative findings related to the ESI process obtained on the ESI+ mode can almost directly be applied also in the ESI- mode.

\section{Introduction}

It has been observed that different solvents have different influence on ionization in electrospray ionization mass spectrometry (ESI/MS) analysis [1, 2]. Most often acetonitrile or methanol in a mixture with water are used as mobile phase in ESI. It has been shown that in many cases ESI response is higher in solutions with higher organic modifier percentage [3]. This may be due to more efficient desolvation of the droplets, allowing them to reach Rayleigh limit faster and eventually generate smaller droplets more rapidly [4].

$\mathrm{pH}$ of the mobile phase also influences ionization in the ESI plume [5]. It has been established that in general basic analytes provide higher sensitivity with more acidic mobile phase in ESI positive mode (ESI+) and acidic analytes with more basic mobile phase in ESI negative mode (ESI-) [2]. It has also been shown that protonated forms of basic analytes can frequently be observed even if the $\mathrm{p} K_{\mathrm{a}}$ (of the protonated analyte) is far below the solutions $\mathrm{pH}$ [6-8]. Similarly deprotonated forms of analytes can be observed when ESI/MS analysis is performed with acidic solutions with 
$\mathrm{pH}$ lower than the analyte $\mathrm{p} K_{\mathrm{a}}[6,9]$. Therefore $\mathrm{pH}$ is an important parameter influencing ionization.

In terms of the mobile phase, the initial composition is generally used to describe the ESI process as the actual composition in the plume is difficult to measure. However, it has been shown that solvent $\mathrm{pH}$ [10-13], organic modifier content [8, 14-17], and droplet size [14, 17-19] change along the plume. The complex dynamics of the ESI process make the transition of ions from solution-phase to gas-phase difficult to model. Atomistic molecular dynamics methods for such simulations have been used [20-25], but are usually limited to the droplets containing up to a few thousand solvent molecules. Therefore, it is advantageous to directly perform optical spectroscopic measurements of physicochemical parameters of droplets and their changes in the electrospray plume in order to correlate the ions observed in the initial sample solution to those observed in the gas phase by the mass-spectrometer.

Fluorescence excitation studies of octaethylporphyrin in the electrospray stream pioneered in using spectroscopy to describe the processes in ESI plume [26]. More recently several researchers [10, 11, 15-18, 27] have developed laser-induced fluorescence strategies to probe properties of ESI plume, e.g. solvent fractionation, solvent polarity, $\mathrm{pH}$ and temperature, and correlate changes with droplet size evolution along the ESI plume. Whereas these experiments were performed by mimicking electrospray sources (i.e. without actual MS measurements), there have also been studies on the aforementioned changes in combination with mass spectrometry $[8,12-14,19]$.

Previous studies have measured either aqueous phase $\mathrm{pH}$ or the $\mathrm{pH}$ of the mobile phase (mixture of water phase and organic solvent) using calibration in water phase. Depending on the organic modifier, it can significantly influence the $\mathrm{pH}$ of the solvent mixture indicating that the conclusions 
drawn from the aqueous phase $\mathrm{pH}$ might be over-simplified. We improve upon the conventional approach by for the first time profiling the $\mathrm{pH}$ in the spray according to the absolute $\mathrm{pH}$ scale [28].

It is expressed as $\mathrm{pH}_{\mathrm{abs}}^{\mathrm{H}_{2} \mathrm{O}}$ values [29], which enables direct comparison of the $\mathrm{pH}$ between different solvents and water (see Experimental section). The acidity of each solvent composition was probed in the aqueous $\mathrm{pH}\left({ }_{\mathrm{w}}^{\mathrm{w}} \mathrm{pH}\right.$, refers to the "conventional" $\mathrm{pH}$ calibrated and measured in water) range from 3.2 to 5.2 using $\mathrm{pH}$-chromic fluorescent dye as the molecular probe.

ESI+ and ESI- mode have only rarely been profiled simultaneously. Cook et al [10] has studied the $\mathrm{pH}$ change in water droplets and Zenobi et al [18] has compared the droplet size for acetonitrile droplets for ESI+ and ESI-. However, usually mobile phase contains both water and organic solvent and the evolution of several parameters $-\mathrm{pH}$, organic modifier content, droplet size occurs simultaneously.

The aim of this study is to quantify the changes occurring in the ESI plume: organic modifier percentage, $\mathrm{pH}$ as well as droplet size change of the "parent" ESI droplets with the diameter range of a few micrometers. For quantitative comparison of $\mathrm{pH}$ changes, the absolute $\mathrm{pH}$ is used which enables comparing different solvents and solvent compositions. Even more so, we will estimate, whether ESI polarity affects the magnitude of mobile phase properties' change in the ESI plume. This enables for the first time to compare the processes occurring in ESI source and aids in better understanding of the differences and similarities of the two modes.

\section{Experimental}

\subsection{Absolute pH measurements}

The conventional pH is defined by IUPAC [30] as given in Eq. (1): 


$$
\mathrm{pH}=-\log a_{H}
$$

where $a_{\mathrm{H}}$ is the relative activity in molal scale. This means that the zero point (standard state) of $\mathrm{pH}$ scale is activity of $1 \mathrm{~mol} / \mathrm{kg}$ of $\mathrm{H}^{+}$solv in the given solvent (or solvent mixture). Therefore, every solvent or solvent mixture has its own $\mathrm{pH}$ scale and none of these scales are comparable due to unknown shifts of the zero points. To add confusion to these different $\mathrm{pH}$ scales there is the question of calibration, which leads to another possibility to define or name $\mathrm{pH}$ scales as ${ }_{\mathrm{s}}^{\mathrm{s}} \mathrm{pH}$ or ${ }_{w}^{\mathrm{s}} \mathrm{pH}$, where subscript shows calibration and superscript measurement medium (s is solvent and w is water). This question is discussed in detail by Rosés [31].

Recently Himmel et al. proposed a unified acidity scale that is based on the absolute standard chemical potential $\mu_{\text {abs }}\left(\mathrm{H}^{+}\right)$of the solvated proton [28] and where the zero point of the scale is the $\mu_{\mathrm{abs}}\left(\mathrm{H}^{+}\right)$of the proton in the gas phase, which is arbitrarily set to $0 \mathrm{~kJ} \mathrm{~mol}^{-1}$. Importantly, this zero point of the scale is universal to all possible media, thereby enabling comparison the acidities of any given media on one scale. This approach is also fully universal in the sense that it does not set any limitations to the solvation sphere of the proton.

The absolute acidities $\mathrm{pH}_{\mathrm{abs}}$ can be calculated via chemical potentials as follows:

$$
\mathrm{pH}_{\mathrm{abs}}=-\frac{\mu_{a b s}\left(\mathrm{H}^{+}, \mathrm{solv}\right)}{R T \ln 10}
$$

where $R$ is the molar gas constant, and $T$ is the absolute temperature and $\mu_{\mathrm{abs}}\left(\mathrm{H}^{+}, \mathrm{solv}\right)$ is calculated as given in Eq. (3)

$$
\mu_{\text {abs }}\left(\mathrm{H}^{+}, \text {solv }\right)=\Delta_{\text {solv }} G^{\ominus}\left(\mathrm{H}^{+}\right)-[\mathrm{pH} \times R T \ln 10]
$$

where $\Delta_{\text {solv }} G^{\ominus}\left(\mathrm{H}^{+}\right)$is Gibbs energy of solvation and $p H$ is the conventional $\mathrm{pH}$. 
As was said by IUPAC already in 1985 [32] an "intersolvental" pH scale would be ultimately referenced to water due to the indisputable key role of water as a solvent. For the same reason absolute acidity is linked to water $\mathrm{pH}$ scale via Gibbs energy of solvation as follows:

$$
\mathrm{pH}_{\mathrm{abs}}^{\mathrm{H}_{2} \mathrm{O}}=\mathrm{pH}_{\mathrm{abs}}+\frac{\Delta_{\text {solv }} G^{\ominus}\left(\mathrm{H}^{+}, \mathrm{H}_{2} \mathrm{O}\right)}{R T \ln 10}
$$

The notion $\mathrm{pH}_{\text {abs }}^{\mathrm{H}_{2} \mathrm{O}}$ means that $\mathrm{pH}$ is expressed on the absolute scale, but values are shifted by a constant in order to make the $\mathrm{pH}_{\mathrm{abs}}$ values directly comparable to the conventional aqueous $\mathrm{pH}$ values (i.e. $\mathrm{pH}_{\mathrm{abs}}^{\mathrm{H}_{2} \mathrm{O}}$ value 7.00 refers to the acidity of the solution where the proton's chemical potential is as high as in aqueous solution with ${ }_{w}^{w} \mathrm{pH}$ 7.00). Thus the unified $\mathrm{pH}$ scale enables to express acidity of any media on a unified scale in the form of familiar aqueous $\mathrm{pH}\left({ }_{\mathrm{w}}^{\mathrm{w}} \mathrm{pH}\right)$ values.

\subsection{Measurements}

Absolute $\mathrm{pH}$ values (Table 1) were obtained by using a Metrohm $713 \mathrm{pH}$ meter in differential potentiometry mode with two metal-coated glass electrodes (Laboratory of Glass Electrochemistry, St. Petersburg State University) as described in [29]. Measurements were made at $(25 \pm 1){ }^{\circ} \mathrm{C}$. Consistency standard deviation of the results was $0.01 \mathrm{pH}$ units and in total 52 measurements were made. Liquid junction potentials and uncertainties were calculated as in ref [29]. Absolute $\mathrm{pH}$ values were measured in bulk solutions and used as reference for calibrating $\mathrm{pH}_{\mathrm{abs}}^{\mathrm{H}_{2} \mathrm{O}}$ in the plume.

Table 1. The acidity of mobile phases expressed as $\mathrm{pH}_{\text {abs }}^{\mathrm{H}_{2} \mathrm{O}}$ values together with measurement uncertainties.

\begin{tabular}{lccc}
\hline Mobile phase $^{\mathbf{a}}$ & $\mathbf{p H}_{\mathrm{abs}}^{\mathbf{H}_{2} \mathbf{O}}$ & $\boldsymbol{u}_{\mathrm{RW}}{ }^{\mathbf{b}}$ & $\boldsymbol{u}_{\mathbf{C}}{ }^{\mathbf{c}}$ \\
\hline $\mathrm{MeCN} /{ }_{\mathbf{w}}^{\mathbf{w}} \mathbf{p H} 5.5080 / 20$ & 8.59 & 0.01 & 0.14 \\
& & & \\
\hline
\end{tabular}




\begin{tabular}{|c|c|c|c|}
\hline $\mathrm{MeCN}_{\mathbf{w}}^{\mathbf{w}} \mathbf{p H} 5.0080 / 20$ & 8.43 & 0.01 & 0.14 \\
\hline $\mathrm{MeCN} /{ }_{\mathbf{w}}^{\mathbf{w}} \mathbf{p H} 5.5075 / 25$ & 8.41 & 0.01 & 0.14 \\
\hline $\mathrm{MeCN} /{ }_{\mathbf{w}}^{\mathbf{w}} \mathbf{p H} 5.5070 / 30$ & 8.23 & 0.01 & 0.14 \\
\hline $\mathrm{MeCN} /{ }_{\mathbf{w}}^{\mathbf{w}} \mathbf{p H} 5.00$ 75/25 & 8.18 & 0.01 & 0.14 \\
\hline $\mathrm{MeCN} /{ }_{\mathbf{w}}^{\mathbf{w}} \mathbf{p H} 4.50$ 80/20 & 8.10 & 0.01 & 0.14 \\
\hline $\mathrm{MeCN} / \mathbf{w} \mathbf{w} \mathbf{p H} 5.0070 / 30$ & 7.94 & 0.01 & 0.14 \\
\hline $\mathrm{MeCN} / \mathbf{w} \mathbf{w} \mathbf{H} 4.5075 / 25$ & 7.80 & 0.01 & 0.14 \\
\hline $\mathrm{MeCN} / \mathbf{w} \mathbf{w} \mathbf{p H} 4.0080 / 20$ & 7.64 & 0.01 & 0.14 \\
\hline $\mathrm{MeCN} /{ }_{\mathbf{w}}^{\mathbf{w}} \mathbf{p H} 4.5070 / 30$ & 7.50 & 0.01 & 0.14 \\
\hline $\mathrm{MeCN} /{ }_{\mathbf{w}}^{\mathbf{w}} \mathbf{p H} 5.5050 / 50$ & 7.49 & 0.01 & 0.14 \\
\hline $\mathrm{MeCN} / \mathbf{w} \mathbf{w} \mathbf{p H} 4.0075 / 25$ & 7.32 & 0.01 & 0.14 \\
\hline $\mathrm{MeCN}_{\mathbf{w}}^{\mathbf{w}} \mathbf{p H} 5.5045 / 55$ & 7.30 & 0.01 & 0.14 \\
\hline $\mathrm{MeCN} / \mathbf{w} \mathbf{w} \mathbf{p H} 3.50$ 80/20 & 7.18 & 0.01 & 0.14 \\
\hline${ }_{\mathbf{w}}^{\mathbf{w}} \mathbf{p H} 7$ (diluted) & 7.13 & 0.01 & 0.14 \\
\hline $\mathrm{MeCN} / \mathbf{w} \mathbf{w} \mathbf{p H} 5.5040 / 60$ & 7.11 & 0.01 & 0.14 \\
\hline $\mathrm{MeCN} / \mathbf{w} \mathbf{w} \mathbf{p H} 5.0050 / 50$ & 7.05 & 0.01 & 0.14 \\
\hline $\mathrm{MeCN} / \mathbf{w} \mathbf{w} \mathbf{p H} 4.0070 / 30$ & 7.03 & 0.01 & 0.14 \\
\hline $\mathrm{MeCN} / \mathbf{w} \mathbf{w} \mathbf{p H} 3.5075 / 25$ & 6.86 & 0.01 & 0.14 \\
\hline $\mathrm{MeCN} / \mathbf{w} \mathbf{w} \mathbf{p H} 5.00$ 45/55 & 6.85 & 0.01 & 0.14 \\
\hline $\mathrm{MeCN} / \mathbf{w} \mathbf{w} \mathbf{p H} 5.0040 / 60$ & 6.62 & 0.01 & 0.14 \\
\hline $\mathrm{MeCN} / \mathbf{w} \mathbf{w} \mathbf{p H} 3.5070 / 30$ & 6.57 & 0.01 & 0.14 \\
\hline $\mathrm{MeCN} / \mathbf{w} \mathbf{w} \mathbf{p H} 4.5050 / 50$ & 6.56 & 0.01 & 0.14 \\
\hline
\end{tabular}




\begin{tabular}{llll}
\hline $\mathrm{MeCN} / \mathbf{w} \mathbf{w} \mathbf{p H} 4.5045 / 55$ & 6.36 & 0.01 & 0.14 \\
$\mathrm{MeCN} / \mathbf{w} \mathbf{w} \mathbf{p H} 4.5040 / 60$ & 6.14 & 0.01 & 0.14
\end{tabular}

${ }^{\mathrm{a}}$ The aqueous phase is $0.1 \%$ formic acid solution titrated with $25 \%$ ammonia solution to the desired ${ }_{\mathrm{w}}^{\mathrm{w}} \mathrm{pH}$.

${ }^{\mathrm{b}}$ Within-lab reproducibility estimates $\left(u_{\mathrm{RW}}\right)$ can be used to evaluate the internal consistency of the measured values. ${ }^{c}$ These combined standard uncertainty estimates $\left(u_{\mathrm{C}}\right)$ can be used to compare the acidities of the solutions in this scale with the acidities of aqueous solutions by conventional $\mathrm{pH}$ measurement.

\section{3 ESI plume profiling}

$\mathrm{MeCN}$ content was profiled in ESI+ and ESI- for solutions initially containing $80 \%$ and $50 \%$ $\operatorname{MeCN}(\mathrm{v} / \mathrm{v})$ from fluorescent measurements of the solvatochromic dye Nile Red [14]. $\mathrm{pH}$ was profiled for mobile phases with initial compositions of acetonitrile/aqueous solution with ${ }_{w}^{\mathrm{w}} \mathrm{pH}$ of 5.0 in the ratio of $80 / 20$ and 50/50, and also for $80 / 20$ mixture with aqueous solution with ${ }_{w}^{\mathrm{w}} \mathrm{pH}$ of 4.00. The corresponding $\mathrm{pH}_{\mathrm{abs}}^{\mathrm{H}_{2} \mathrm{O}}$ changes are listed in Table 2. The change of the droplet size was studied for acetonitrile/water 80/20 and 50/50 (v/v) mixtures with ${ }_{w}^{w} \mathrm{pH}$ of 5.00, and also for 80/20 mixture with initial aqueous solution with ${ }_{\mathrm{w}}^{\mathrm{w}} \mathrm{pH}$ of 4.00 .

The experimental setup profiling the spray plume consists of an excitation laser and two different optical detection systems mounted on a moving stage. It is coupled with a Single Quad 6100 mass spectrometer equipped with a modified Agilent Jet Stream ESI source (Agilent Technologies, Santa Clara, CA, USA) in order to allow the laser injection into the plume and the epifluorescence measurements. Used ESI parameters were: capillary voltage 3500/-3500 V, nebulizing gas pressure 15 psi, drying gas flow rate $7 \mathrm{~L} / \mathrm{min}$, drying gas temperature $300{ }^{\circ} \mathrm{C}$, sheath gas flow rate $1 \mathrm{~L} / \mathrm{min}$ and temperature $80{ }^{\circ} \mathrm{C}$. Solutions were introduced in the ionization source at $50 \mu \mathrm{L} \mathrm{min}{ }^{-1}$ flow rate with a KDS100 syringe pump (KD Scientific, Holliston, MA, USA).

The temperature of the droplets was not profiled in this study. However previous studies performed with methanol droplets have shown either a slight increase of temperature [19] or some decrease 
[33] along the plume. The temperature of the plume in the referred studies was found to be between 295 and $307 \mathrm{~K}$.

A continuous laser $(\lambda=473 \mathrm{~nm})$ emitting in a single longitudinal mode was used to profile ESI plume. The output power of the laser was around $500 \mathrm{~mW}$ and its beam diameter is $1.5 \mathrm{~mm}$ (divergence $1 \mathrm{mrad}$ ). The laser is injected through the objective using two reflecting protected aluminum flat mirrors $(R>90 \%)$. The laser beam is focused into the spray and the fluorescence is collected via an objective used in an epifluorescence configuration. Fluorescence spectra from ESI plume were recorded, point by point (pixel size $500 \mu \mathrm{m}$ ), by an ultra-compact spectrophotometer (B\&WTek Inc., Newark, DE, USA). The plume was profiled for $15 \mathrm{~mm}$ starting from ESI needle tip, except for $50 \% \mathrm{MeCN}$ solution where plume was profiled for $13 \mathrm{~mm}$ due to poor solubility of the fluorescent probe.

The obtained raw data was processed using OriginPro 7.0 software. Profiles of $\mathrm{pH}$ and solvent composition in the ESI plume (Figures 1a and 1b) were determined from calibrations in different solutions.

For droplet size profiling (Figure 1c), a Fraunhofer diffraction setup is implemented on the other side of the ESI source and the same excitation laser is used. A system of two cylindrical lenses is used to direct the diffracted light on the Charge Coupled Device (CCD) camera guppy F-080B/C FireWire (Allied Vision Technologies, Stadtroda, Germany). The first lens $(f=100 \mathrm{~mm})$ allows the collection of the scattered light for a solid angle ranging from $\boldsymbol{\theta}_{\min }=\mathbf{6 . 7}^{\circ}$ to $\boldsymbol{\theta}_{\max }=\mathbf{1 7 . 7 ^ { \circ }}$ with respect to the laser beam axis, whereas the second one $(f=150 \mathrm{~mm})$ is used to focus the light on the CCD camera. The exposure time was set to $80 \mathrm{~ms}$ (with a time base of $20 \mu \mathrm{s}$ ) and 20 images are recorded for each point. 
After plotting the signal intensity as a function of the scattering angle, using a homemade software, comparison with the Mie theory [34] allowed us to obtain the droplet size with accuracy better than $2.5 \%$ due to the high sensitivity of the interference pattern to the size for $\mu \mathrm{m}$-sized droplets.

\subsection{Compounds}

The fluorescent $\mathrm{pH}$ indicator 5(6)-carboxy-2',7'-dichlorofluoresceine (Sigma, $\geq 95 \%$ ) and solvatochromic Nile Red (Invitrogen, Cergy, Pontoise, France) were used as fluorescent probes. Acetonitrile (J.T.Baker, Deventer, Netherlands, HPLC grade), MilliQ water (Millipore Advantage A10 MILlIPORE GmbH, Molsheim, France), formic acid (Fluka, 98\%, Buchs, Switzerland), ammonium hydroxide (Lach:Ner, 25\%, Czech Republic), dimethyl sulphoxide (Sigma, Steinheim, Germany), buffer pH 7.00 (Fluka, Buchs, Switzerland) were used. Water phase pH values ( $\left.{ }_{w}^{w} \mathrm{pH}\right)$ were measured with Hanna Instruments pH211 Microprocessor pH Meter equipped with a 4 mmdiameter microelectrode ( $\mathrm{Pt} / / 3.5 \mathrm{~mol} / \mathrm{L} \mathrm{KCl}+\mathrm{AgCl})$.

First of all, the chromism of Nile Red $(20 \mu \mathrm{M})$ was calibrated in MeCN/water binary solvent mixtures. Variation in the $\mathrm{MeCN} /$ water ratio induces a shift of the maximum emission wavelength. The solvent composition of an unknown solution can be determined based on the $\lambda_{\max }$ using the calibration curve.

For $\mathrm{pH}$ measurements, stock solutions containing $0.1 \mathrm{mM}$ of 5(6)-carboxy-2',7'dichlorofluoresceine were made in dimethyl sulphoxide. From the initial solution, $10 \mu \mathrm{M}$ binary acetonitrile/water solutions were prepared, where the ${ }_{w}^{w} \mathrm{pH}$ varied: 3.50, 4.00, 4.50, 5.03, 6.04, and 6.51. Water phase solutions were prepared by first making $0.1 \%$ formic acid solution and then adjusting $\mathrm{pH}$ by adding the ammonium hydroxide solution to the desired ${ }_{\mathrm{w}}^{\mathrm{w}} \mathrm{pH}$. The obtained water phase solutions were then mixed in different ratios with acetonitrile so that acetonitrile content in 
the calibration solutions was $80 \%, 75 \%, 70 \%, 65 \%, 60 \%, 55 \%, 50 \%, 45 \%, 40 \%$. In order to establish calibration curves, fluorescence spectra of all the obtained 54 mixtures were measured, in solution and logarithm of the ratios of fluorescence emission intensities was calculated.

\section{Results}

The results of MeCN content and $\mathrm{pH}_{\mathrm{abs}}^{\mathrm{H}_{2} \mathrm{O}}$ in the ESI plume for all studied mobile phases are brought in Table 2. In all cases, the $\mathrm{MeCN}$ content decrease across the plume is 5.3 to $7.5 \%$ (percentage point), as acetonitrile is more readily vaporized during the evaporation process of the droplets. These changes in $\mathrm{MeCN}$ content in the ESI plume have been taken into account for the determination of the $\mathrm{pH}$. This means for every point in the $\mathrm{pH}$ calibration curve the corresponding MeCN content percentage was used. For all mobile phases the ESI+ mode has somewhat smaller change in $\mathrm{MeCN}$ content, however the difference is insignificant.

Table 2. Change of MeCN content and $\mathrm{pH}_{\mathrm{abs}}^{\mathrm{H}_{2} \mathrm{O}}$ in the ESI plume $(y=3 \mathrm{~mm}), x_{\max }=15 \mathrm{~mm}$ from the needle tip, except for $50 \% \mathrm{MeCN}$ initial content, where $x_{\max }=13 \mathrm{~mm}$.

\begin{tabular}{|c|c|c|c|c|c|c|}
\hline Initial $\mathrm{MeCN}$ content & \multicolumn{2}{|c|}{$80 \%$} & \multicolumn{2}{|c|}{$80 \%$} & \multicolumn{2}{|c|}{$50 \%$} \\
\hline Initial ${ }_{\mathrm{w}}^{\mathrm{w}} \mathrm{pH}$ & \multicolumn{2}{|c|}{4.00} & \multicolumn{2}{|c|}{5.03} & \multicolumn{2}{|c|}{5.03} \\
\hline Initial $\mathrm{pH}_{\mathrm{abs}}^{\mathrm{H}_{2} \mathrm{O}}$ & \multicolumn{2}{|c|}{7.64} & \multicolumn{2}{|c|}{8.43} & \multicolumn{2}{|c|}{7.05} \\
\hline ESI mode & ESI+ & ESI- & ESI+ & ESI- & ESI+ & ESI- \\
\hline $\begin{array}{l}\Delta \mathrm{MeCN} \text { content } \% \\
\text { (percentage point) }\end{array}$ & $5.6 \%$ & $5.7 \%$ & $5.3 \%$ & $7.4 \%$ & $7.0 \%$ & $7.5 \%$ \\
\hline $\mathrm{pH}_{\mathrm{abs}}^{\mathrm{H}_{2} \mathrm{O}}\left({ }_{\mathrm{w}}^{\mathrm{w}} \mathrm{pH}\right)$ at $x=0 \mathrm{~mm}$ & $\begin{array}{c}7.47 \\
(3.78)\end{array}$ & $\begin{array}{c}7.81 \\
(4.27)\end{array}$ & $\begin{array}{c}8.20 \\
(4.80)\end{array}$ & $\begin{array}{c}8.49 \\
(5.14)\end{array}$ & $\begin{array}{c}6.83 \\
(4.82)\end{array}$ & $\begin{array}{c}7.19 \\
(5.16)\end{array}$ \\
\hline $\mathrm{pH}_{\mathrm{abs}}^{\mathrm{H}_{2} \mathrm{O}}\left(\mathrm{w}_{\mathrm{w}}^{\mathrm{w}} \mathrm{pH}\right)$ at $x_{\max }$ & $\begin{array}{c}6.66 \\
(3.21)\end{array}$ & $\begin{array}{c}7.19 \\
(3.91)\end{array}$ & $\begin{array}{c}7.52 \\
(4.28)\end{array}$ & $\begin{array}{c}7.82 \\
(4.73)\end{array}$ & $\begin{array}{c}6.28 \\
(4.54)\end{array}$ & $\begin{array}{c}6.62 \\
(4.88)\end{array}$ \\
\hline$\underset{\mathrm{pH}_{\mathrm{abs}}^{\mathrm{H}_{2} \mathrm{O}}\left(\Delta_{\mathrm{w}}^{\mathrm{w}} \mathrm{pH}\right) \text { in } \mathrm{ESI}}{\text { plume }}$ & $\begin{array}{c}0.81 \\
(0.57)\end{array}$ & $\begin{array}{c}0.62 \\
(0.36)\end{array}$ & $\begin{array}{c}0.68 \\
(0.52)\end{array}$ & $\begin{array}{c}0.67 \\
(0.41)\end{array}$ & $\begin{array}{c}0.55 \\
(0.28)\end{array}$ & $\begin{array}{c}0.57 \\
(0.28)\end{array}$ \\
\hline
\end{tabular}

The $\mathrm{pH}_{\mathrm{abs}}^{\mathrm{H}_{2} \mathrm{O}}$ at the ESI needle tip $(x=0 \mathrm{~mm})$ is different (confirmed by $t$-test) from the $\mathrm{pH}_{\text {abs }}^{\mathrm{H}_{2} \mathrm{O}}$ of the initial solution (Table 2). The $\mathrm{pH}_{\mathrm{abs}}^{\mathrm{H}_{2} \mathrm{O}}$ change from 0.06 to $0.23 \mathrm{pH}$ units is observed between 
the bulk mobile phase and mobile phase in the needle tip. The $\mathrm{pH}_{\mathrm{abs}}^{\mathrm{H}_{2} \mathrm{O}}$ change along the plume is visualized in Figure 1b. It can be observed that the $\mathrm{pH}_{\mathrm{abs}}^{\mathrm{H}_{2} \mathrm{O}}$ of the solution decreases steadily along the ESI plume (i.e. becomes more acidic). In the case of a $50 \% \mathrm{MeCN}$ content in the initial solution, the change in the $\mathrm{pH}$ is lower than for $80 \%$ initial $\mathrm{MeCN}$ content. However, the droplets for $50 / 50$ acetonitrile/ ${ }_{w}^{\mathrm{w}} \mathrm{pH} 5.00$ water phase are more acidic according to $\mathrm{pH}_{\mathrm{abs}}^{\mathrm{H}_{2} \mathrm{O}}$ than for $80 / 20$ acetonitrile/ ${ }_{w}^{\mathrm{w}} \mathrm{pH} 4.00$. This shows that ${ }_{\mathrm{w}}^{\mathrm{w}} \mathrm{pH}$ solely is not suitable for describing the acidity of mobile phase.

The largest difference of the $\mathrm{pH}_{\mathrm{abs}}^{\mathrm{H}_{2} \mathrm{O}}$ for ESI+ and ESI- down the plume evolution was observed for mobile phase containing $80 / 20 \mathrm{MeCN} /{ }_{\mathrm{w}}^{\mathrm{w}} \mathrm{pH} 4.00$ and the change up to $0.81 \mathrm{pH}$ units. 


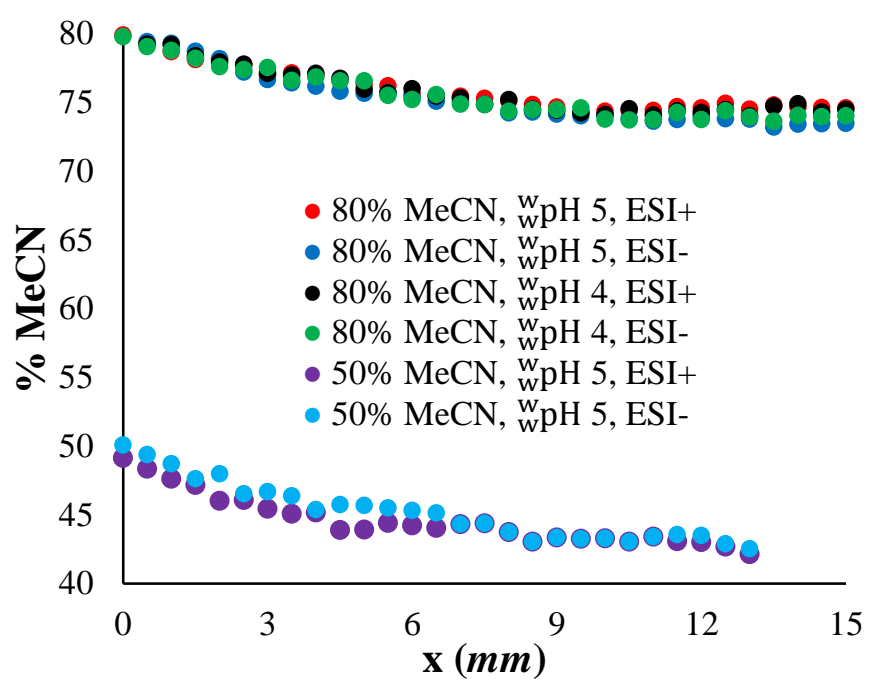

a.

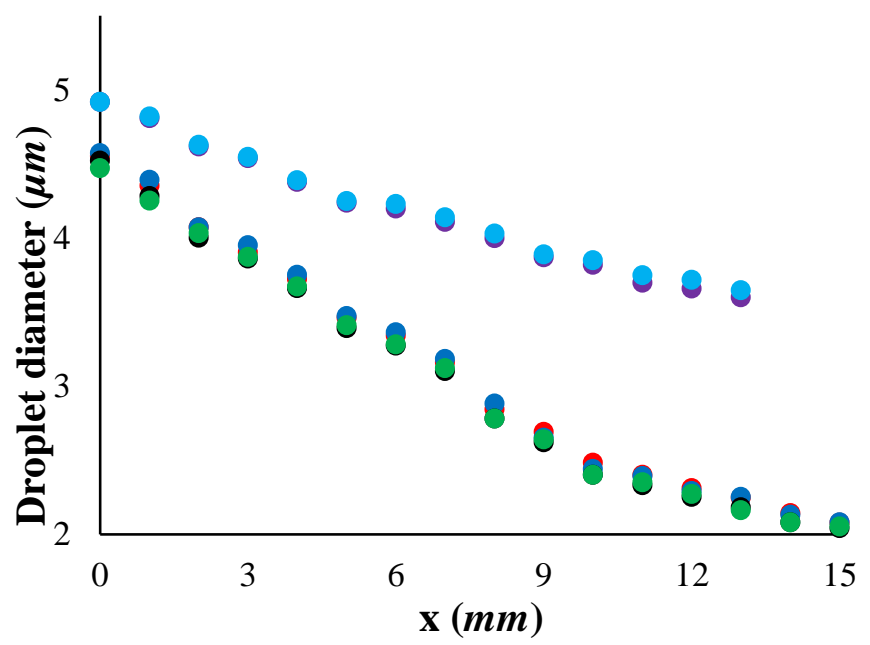

c.

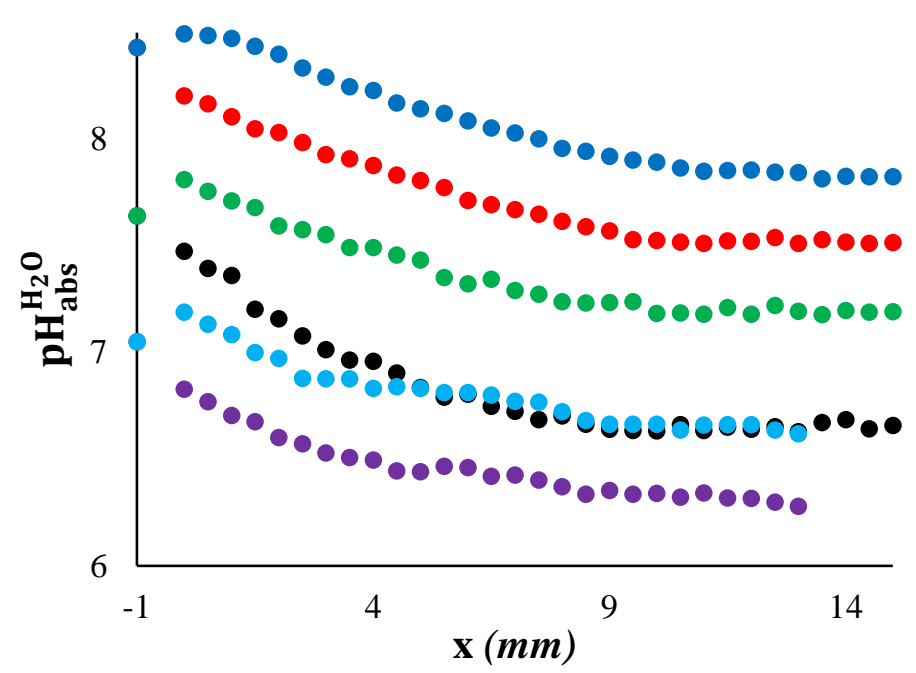

b.

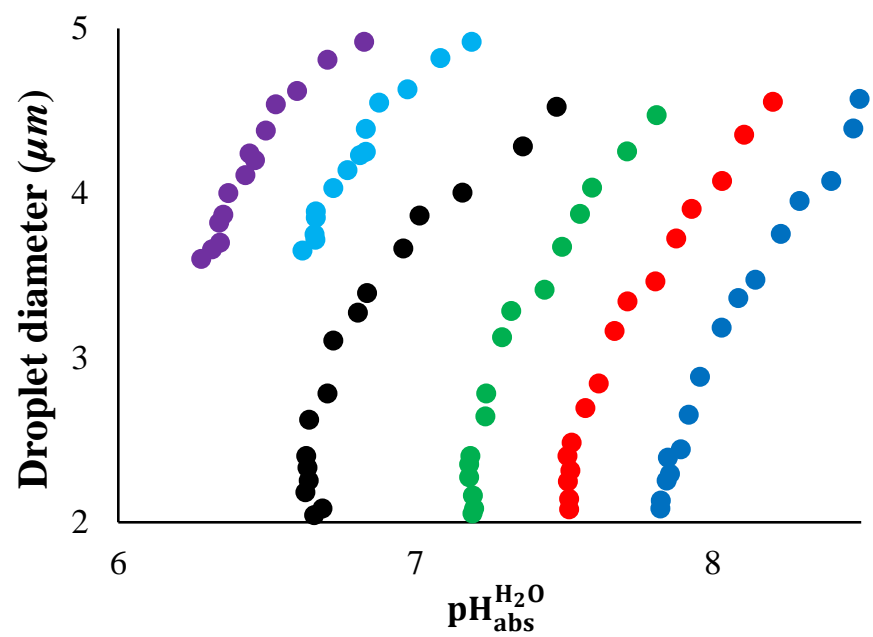

d.

Figure 1 Change in (a) MeCN content in the middle of the ESI plume $(y=3 \mathrm{~mm}),(\mathrm{b}) \mathbf{p} \mathbf{H}_{\mathbf{a b s}}^{\mathbf{H}_{\mathbf{2}} \mathbf{0}}$ in the middle of the plume. $\mathrm{pH}$ in $x=-1 \mathrm{~mm}$ is the $\mathbf{p H}_{\mathbf{a b s}}^{\mathbf{H}_{2} \mathbf{O}}$ of the initial mobile phase, (c) average droplet diameter in the spray plume versus the axial distance $x$ from the emitter tip (average error is $\pm 0.6 \mu \mathrm{m}$ ) (d) average droplet diameter versus the $\mathbf{p H}_{\mathrm{abs}}^{\mathbf{H}_{2} \mathbf{O}}$ in ESI plume. The legend is the same for $\mathrm{a}, \mathrm{b}, \mathrm{c}$ and $\mathrm{d}$.

The droplet size was determined by Mie scattering measurements. The comparison of the projection of the signal intensity as a function of the scattering angle with the Mie theory allows to determine the average droplet diameter at each point in the ESI plume, for the previously determined solvent compositions. The droplets shrink as they move downstream, due to the 
evaporation process. Note that the reported droplet size is an average of the size of droplets within a pixel, which is an area of $500 \mu \mathrm{m} \times 500 \mu \mathrm{m}$. Moreover, the droplets constituting the ESI plume are polydispersed. The droplet size distribution for each pixel is found to be Gaussian with a standard deviation $\sigma$ ranging from $1 \%$ to $2.5 \%$. The droplet diameter is decreasing along the plume from $4.5 \mu \mathrm{m}$ to $2 \mu \mathrm{m}$ for the $\mathrm{MeCN} /$ water $80 / 20$ solvent mixture. For the 50/50 mixture, the initial droplet diameter is higher $(4.9 \mu \mathrm{m})$ and the solvent evaporation is less efficient, leading to droplet diameter of $3.6 \mu \mathrm{m}$ at $x=13 \mathrm{~mm}$ from the emitter tip. However, droplet size measurements demonstrate that droplet diameter change is independent of the ESI mode.

\subsection{Discussion}

In this paper for the first time we simultaneously measure plume parameters for ESI+ [16, 27, 33] and ESI- [14] for acidic mobile phase. Though both modes have been used in plume profiling before usually one mode has been used at a time. Due to different conditions, instrumentation, measurement method, etc the results of such measurements thus far have not allowed direct comparison of ESI+ and ESI-.

Secondly, in this paper we present the study of the most acidic mobile phase profiled so far. In ESI+ acidic mobile phases are much more often used than neutral or basic mobile phases and are therefore of great interest. The main difficulty was to find a dye with low enough $\mathrm{p} K_{\mathrm{a}}$ value, with acceptable solubility in the mobile phase and significant change of spectral features with $\mathrm{pH}$. The lowest $\mathrm{pH}$ that could be profiling was ${ }_{\mathrm{w}}^{\mathrm{w}} \mathrm{pH}$ of 3.00 .

Thirdly, it is the first time plume profiling is connected with $\mathrm{pH}_{\mathrm{abs}}^{\mathrm{H}_{2} \mathrm{O}}$ measurements, therefore allowing to compare acidities for plumes with different organic solvent content. This on the other 
hand makes results of this work also comparable with future researches, independent of the mobile phase of use there.

The obtained fluorescence spectra is an average of droplets present in the size of the laser beam ( $\sim 1 \mathrm{~mm}$ ). So the $\mathrm{pH}$ and mobile phase composition measured correspond to an area of $\sim 0.78 \mathrm{~mm}^{2}$ in the ESI plume and not for an unique droplet. The droplets profiled in this study are the large parent droplets (in a micrometer scale) observed in the ESI plume. They are in different stages of development: (1) approaching Rayleigh limit, (2) close to the Rayleigh limit and (3) already undergone Coulomb explosion and emitted significant amount of excess charge via formation of smaller offspring droplets. Therefore not all of the droplets are at the same stage and profiling gives us the average of these droplets.

It was observed that the mobile phase became more acidic (compared to the initial acidity) at the needle tip $(x=0 \mathrm{~mm})$ in the ESI+ mode, whereas in ESI- it became more basic. The $\mathrm{pH}_{\mathrm{abs}}^{\mathrm{H}_{2} \mathrm{O}}$ measurements at this point are not yet influenced by the selective evaporation that occurs in the plume, as the measurements are made directly in the needle tip. This is also observable on Figure 1a, which shows the acetonitrile content along the plume starting from the needle tip. The change in $\mathrm{pH}_{\mathrm{abs}}^{\mathrm{H}_{2} \mathrm{O}}$ is caused by the electrochemical reactions taking place in the very end on the needle capillary. In ESI+ mode the electrochemical reaction creates an additional amount of protons from water or additives, while in ESI- hydroxyl ions are generated or protons are neutralized [10-12, $35,36]$.

The $\mathrm{pH}_{\text {abs }}^{\mathrm{H}_{2} \mathrm{O}}$ difference between bulk mobile phase and mobile phase on the capillary tip for ESI+ and ESI- modes in all mobile phases was up to $0.23 \mathrm{pH}_{\mathrm{abs}}^{\mathrm{H}_{2} \mathrm{O}}$ units. Van Berkel et al [35] have 
previously found and calculated that the change could be in the order of 2 or more $\mathrm{pH}$ units. This may result from the fact, that in their study pure water without buffering agent was used. Additionally, predictive calculations usually do not account for the shift of acid-base equilibria due to organic solvent content in the mobile phase (i.e. calculations/measurements are carried out in aqueous phase and organic phase influence is considered small) [@]. The $\mathrm{p} K_{\mathrm{a}}$ values of carboxylic acids increase markedly with higher organic modifier content therefore the generated protons are readily adsorbed by the buffering anions (that become stronger bases with the addition of organic modifier). Therefore the addition or removal of protons has a much smaller effect on the overall change on $\mathrm{pH}_{\mathrm{abs}}^{\mathrm{H}_{2} \mathrm{O}}$.

The $\mathrm{pH}_{\mathrm{abs}}^{\mathrm{H}_{2} \mathrm{O}}$ change occurring between bulk phase and droplets in the needle tip is significant. However the absolute value of $\mathrm{pH}_{\mathrm{abs}}^{\mathrm{H}_{2} \mathrm{O}}$ change is very similar for ESI+ (up to 0.23 units) and ESI(up to 0.17 units). Therefore, the absolute differences in the changes of $\mathrm{pH}_{\mathrm{abs}}^{\mathrm{H}_{2} \mathrm{O}}$ occurring in the needle tip for ESI+ and ESI- are statistically insignificantly different. Based on this, it is impossible to decide over the efficiency of electrochemical reaction between ESI modes and mobile phases.

For all studied mobile phases and in both modes it was observed, that the solutions become more acidic along the plume. This is anticipated since in the spray acetonitrile is more readily vaporized and thus the content of $\mathrm{MeCN}$ in the droplets decreases along the plume, causing an increase of water content, resulting in increase of formic acid (the aqueous phase consists of $0.1 \%$ formic acid solution titrated with $25 \%$ ammonia solution to the desired $\mathrm{pH}$ ) dissociation thereby turning the solution more acidic. The influence of solvent composition change on basicity of ammonia is less important because (1) basicity of bases is less influenced by adding organic solvent [29] and (2) the used $\mathrm{pH}$ range is far from the $\mathrm{p} K_{\mathrm{a}}$ of $\mathrm{NH}_{4}{ }^{+}$. The $\mathrm{pH}$ change in the plume is in general similar 
to that expected and also previously demonstrated [12]. Therefore showing that tendencies found previously for neutral and basic mobile phases are also valid for acidic mobile phases.

The decrease of $\mathrm{pH}_{\mathrm{abs}}^{\mathrm{H}_{2} \mathrm{O}}$ along the plume is very similar in ESI+ and ESI- resulting in almost parallel evolution of lines (within one mobile phase) in Figure 1b. Therefore the $\mathrm{pH}_{\mathrm{abs}}^{\mathrm{H}_{2} \mathrm{O}}$ difference for ESI+ and ESI- generated by the electrochemical reaction in the needle tip remains essentially the same throughout the plume in spite of acetonitrile evaporation. Only in the case where buffer solution with ${ }_{\mathrm{w}}^{\mathrm{w}} \mathrm{pH}$ of 4.00 was used, the aqueous phase of ESI+ becomes more acidic and ESI- becomes somewhat less acidic, making up the $\mathrm{pH}_{\mathrm{abs}}^{\mathrm{H}_{2} \mathrm{O}}$ difference of 0.53 units at the maximum profiling length. If electrochemical reactions would be of the same efficiency for all mobile phases and the organic solvent evaporation rates would be indistinguishable, as observed form Figure 1a, we would expect that more acidic mobile phase obeys less $\mathrm{pH}$ change than the less acidic (also keeping in mind, that the buffering capacity for this studied mobile phase is much higher).

Also it was observed that $\mathrm{pH}_{\mathrm{abs}}^{\mathrm{H}_{2} \mathrm{O}}$ change is larger for mobile phase containing $80 \%$ of acetonitrile than for mobile phase containing $50 \%$ of acetonitrile. The probable reasons are: (1) the profiled length is longer (15 mm versus $13 \mathrm{~mm}$ in the case of $50 \% \mathrm{MeCN}$ ) and (2) the change in the droplet size is larger (Figure 1c and 1d). The first possibility may be ruled out, as the plateau of the $\mathrm{pH}$ change has already been achieved at $x=13 \mathrm{~mm}$. The droplet size change, however, is in almost linear relation with $\mathrm{pH}_{\mathrm{abs}}^{\mathrm{H}_{2} \mathrm{O}}$, see Figure 1d. It is observed, that the droplet size changes more for mobile phase with $80 \%$ of $\mathrm{MeCN}$. MeCN evaporates more readily from solution with higher MeCN content [14]: both 50/50 and 80/20 mobile phases lose about 5\% of acetonitrile, therefore the total acetonitrile loss (and thereby the increase in water content leading to increased 
dissociation of formic acid) for the latter is higher. Solvent fractionation is less efficient when the initial water content is higher.

It is worth mentioning though that the $\mathrm{pH}_{\mathrm{abs}}^{\mathrm{H}_{2} \mathrm{O}}$ differences are much smaller than have been predicted by theoretical calculations [25].

Also it is important to note that it is not known whether the droplets formed in ESI are actually in their equilibrium. In previous studies it has been shown that some compounds may retain their liquid phase structures (charge location) due to kinetical trapping [37] - meaning that the drying of the droplets in ESI is too fast for the droplets to reach the actual equilibrium. Therefore it is also likely that at least some of the droplets profiled in our work have not reached the chemical equilibria (including acid-base equilibrium). However calculations can only be made based on the

\section{assumption of reached equilibria.}

The method used allows us to profile the droplets down to $0.5 \mu \mathrm{m}$ in diameter, therefore indicating two mechanisms influencing the plume evolution. First, the drying of the droplets due to heated drying gas. In this process the more volatile mobile phase component evaporates faster, but the changes are expected to be similar for the two ESI modes.

Secondly, the fission of the charged nanodroplets from the parent droplets. This mechanism can have an effect on the composition of the remaining part of the parent droplet and is expected to influence ESI+ and ESI- mode differently. In ESI+ and ESI- ions of different type are removed from the parent droplets during ejection of nanodroplets, therefore facilitating $\mathrm{pH}_{\mathrm{abs}}^{\mathrm{H}_{2} \mathrm{O}}$ change in different directions. Each fission of one nanodroplets removes about $20 \%$ of the excess charge from the parent droplet $[38,39]$. The general amount of excess charge can be estimated on the basis of $\mathrm{pH}$ change from bulk mobile phase to mobile phase in the needle tip. It is obvious that it 
changes from mobile phase to mobile phase, but based on the data obtained in this study it can be expected that the fraction of charge present as excess charge reaches several tens of per cent of the overall excess charge [40]. Therefore if the fission of nanodroplets would be a dominant process changing the composition of the parent droplets we would expect: (1) a significantly different $\mathrm{pH}_{\mathrm{abs}}^{\mathrm{H}_{2} \mathrm{O}}$ profile for ESI+ and ESI- along the plume and (2) more significant changes in the droplets $\mathrm{pH}_{\mathrm{abs}}^{\mathrm{H}_{2} \mathrm{O}}$ along the plume.

These findings are very important from two aspects. First, for modelling ESI process it is obvious that desolvation due to drying is much more important than the fission of nanodroplets. This means that similar models for ESI+ and ESI- mode can theoretically be constructed and this could also serve as a validation criterion for such models.

Secondly, for practitioners it shows that qualitative findings related to the ESI process obtained on the ESI+ mode can almost directly be applied also in the ESI- mode. However the importance of desolvation gas is huge and therefore quantitative findings are transferable only within one set of gas parameters between ESI+ and ESI-.

\section{Conclusions}

Changes in organic content percentage, $\mathrm{pH}$ and droplet size are very similar for both ESI+ and ESI- indicating that in these means the two modes are similar. In all cases mobile phases became more acidic along the plume, but less than predicted by calculations. The results aid in understanding the conditions of where the ionization occurs better and enable to directly compare the two polarities used for ESI ionization efficiency measurements. This is very promising and our group is currently working on establishing solid quantitative link between the ionization 
efficiencies in the two ionization modes, which would enable deciding whether ESI+ or ESI- is more promising for a given analyte.

\section{Acknowledgements}

This work was supported by Personal Research Funding Project 34 from the Estonian Research Council, and by national scholarship program Kristjan Jaak, which is funded and managed by the Archimedes Foundation in collaboration with the Ministry of Education and Research. The research leading to these results has received funding from Agilent Technologies with an award through Agilent's Application and Core Technology University Research Program (Grant ID 2243). The work of AH and IL was supported by the Institutional funding project IUT20-14 from the Estonian Ministry of Education and Research. 


\subsection{References}

1. Cech, N.B., Enke, C.G.: Practical implications of some recent studies in electrospray ionization fundamentals. Mass Spectrom. Rev. 20, 362-387 (2001)

2. Cole, R.B.: Electrospray and MALDI Mass Spectrometry: fundamentals, instrumentation, practicalities, and biological applications. Wiley, Hoboken (2010)

3. Kruve, A.: Influence of mobile phase, source parameters and source type on electrospray ionization efficiency in negative ion mode: Influence of mobile phase in ESI/MS. J. Mass Spectrom. 51, 596-601 (2016). doi:10.1002/jms.3790

4. Zhou, S., Hamburger, M.: Effects of solvent composition of molecular ion response in electrospray mass spectrometry: investigation of the ionization process. Rapid Commun. Mass Spectrom. 9, 1516-1521 (1995)

5. Liigand, J., Laaniste, A., Kruve, A.: pH Effects on Electrospray Ionization Efficiency. J. Am. Soc. Mass Spectrom. 28, 461-469 (2017). doi:10.1007/s13361-016-1563-1

6. Zhou, S., Cook, K.D.: Protonation in electrospray mass spectrometry: wrong-way-round or right-way-round? J. Am. Soc. Mass Spectrom. 11, 961-966 (2000)

7. Oss, M., Kruve, A., Herodes, K., Leito, I.: Electrospray Ionization Efficiency Scale of Organic Compounds. Anal. Chem. 82, 2865-2872 (2010). doi:10.1021/ac902856t

8. Liigand, J., Kruve, A., Leito, I., Girod, M., Antoine, R.: Effect of Mobile Phase on Electrospray Ionization Efficiency. J. Am. Soc. Mass Spectrom. 25, 1853-1861 (2014). doi:10.1007/s13361-014-0969-x

9. Kruve, A., Kaupmees, K., Liigand, J., Leito, I.: Negative Electrospray Ionization via Deprotonation: Predicting the Ionization Efficiency. Anal. Chem. 86, 4822-4830 (2014). doi:10.1021/ac404066v

10. Zhou, S., Edwards, A.G., Cook, K.D., Van Berkel, G.J.: Investigation of the Electrospray Plume by Laser-Induced Fluorescence Spectroscopy. Anal. Chem. 71, 769-776 (1999). doi:10.1021/ac981259r

11. Zhou, S., Prebyl, B.S., Cook, K.D.: Profiling pH Changes in the Electrospray Plume. Anal. Chem. 74, 4885-4888 (2002). doi:10.1021/ac025960d

12. Girod, M., Dagany, X., Antoine, R., Dugourd, P.: Relation between charge state distributions of peptide anions and $\mathrm{pH}$ changes in the electrospray plume. A mass spectrometry and optical spectroscopy investigation. Int. J. Mass Spectrom. 308, 41-48 (2011). doi:10.1016/j.ijms.2011.07.020

13. Girod, M., Antoine, R., Dugourd, P., Love, C., Mordehai, A., Stafford, G.: Basic Vapor Exposure for Tuning the Charge State Distribution of Proteins in Negative Electrospray Ionization: Elucidation of Mechanisms by Fluorescence Spectroscopy. J. Am. Soc. Mass Spectrom. 23, 1221-1231 (2012). doi:10.1007/s13361-012-0375-1

14. Girod, M., Dagany, X., Boutou, V., Broyer, M., Antoine, R., Dugourd, P., Mordehai, A., Love, C., Werlich, M., Fjeldsted, J., Stafford, G.: Profiling an electrospray plume by laserinduced fluorescence and Fraunhofer diffraction combined to mass spectrometry: influence of size and composition of droplets on charge-state distributions of electrosprayed proteins. Phys. Chem. Chem. Phys. 14, 9389-9396 (2012)

15. Zhou, S., Cook, K.D.: Probing Solvent Fractionation in Electrospray Droplets with LaserInduced Fluorescence of a Solvatochromic Dye. Anal. Chem. 72, 963-969 (2000). doi:10.1021/ac990912n 
16. Wang, R., Zenobi, R.: Evolution of the solvent polarity in an electrospray plume. J. Am. Soc. Mass Spectrom. 21, 378-385 (2010). doi:10.1016/j.jasms.2009.10.022

17. Hopkins, R.J., Reid, J.P.: Evaporation of Ethanol/Water Droplets: Examining the Temporal Evolution of Droplet Size, Composition and Temperature. J. Phys. Chem. A. 109, 7923-7931 (2005). doi:10.1021/jp0516543

18. Wortmann, A., Kistler-Momotova, A., Zenobi, R., Heine, M.C., Wilhelm, O., Pratsinis, S.E.: Shrinking droplets in electrospray ionization and their influence on chemical equilibria. J. Am. Soc. Mass Spectrom. 18, 385-393 (2007). doi:10.1016/j.jasms.2006.10.010

19. Soleilhac, A., Dagany, X., Dugourd, P., Girod, M., Antoine, R.: Correlating Droplet Size with Temperature Changes in Electrospray Source by Optical Methods. Anal. Chem. 87, 8210-8217 (2015). doi:10.1021/acs.analchem.5b00976

20. Oh, M.I., Consta, S.: Stability of a Transient Protein Complex in a Charged Aqueous Droplet with Variable pH. J. Phys. Chem. Lett. 8, 80-85 (2017). doi:10.1021/acs.jpclett.6b02319

21. Sharawy, M., Consta, S.: How do non-covalent complexes dissociate in droplets? A case study of the desolvation of dsDNA from a charged aqueous nanodrop. Phys Chem Chem Phys. 17, 25550-25562 (2015). doi:10.1039/C5CP04331J

22. Ahadi, E., Konermann, L.: Molecular Dynamics Simulations of Electrosprayed Water Nanodroplets: Internal Potential Gradients, Location of Excess Charge Centers, and "Hopping” Protons. J. Phys. Chem. B. 113, 7071-7080 (2009). doi:10.1021/jp810599f

23. Sharawy, M., Consta, S.: Characterization of "Star" Droplet Morphologies Induced by Charged Macromolecules. J. Phys. Chem. A. 120, 8871-8880 (2016). doi:10.1021/acs.jpca.6b08486

24. Consta, S., Oh, M.I., Malevanets, A.: New mechanisms of macroion-induced disintegration of charged droplets. Chem. Phys. Lett. 663, 1-12 (2016). doi:10.1016/j.cplett.2016.08.001

25. Malevanets, A., Consta, S.: Variation of droplet acidity during evaporation. J. Chem. Phys. 138, 184312 (2013). doi:10.1063/1.4804303

26. Chillier, X.F.D., Monnier, A., Bill, H., Gulacar, F.O., Buchs, A., McLuckey, S.A., Van Berkel, G.J.: A Mass Spectrometry and Optical Spectroscopy Investigation of Gas-phase Ion Formation in Electrospray. Rapid Commun. Mass Spectrom. 10, 299-304. doi:10.1002/(SICI)1097-0231(199602)10:3<299::AID-RCM502>3.0.CO;2-U

27. Davis, D., Portelius, E., Zhu, Y., Feigerle, C., Cook, K.D.: Profiling an Electrospray Plume Using Surface-Enhanced Raman Spectroscopy. Anal. Chem. 77, 8151-8154 (2005). doi:10.1021/ac0511039

28. Himmel, D., Goll, S.K., Leito, I., Krossing, I.: Anchor Points for the Unified Brønsted Acidity Scale: The rCCC Model for the Calculation of Standard Gibbs Energies of Proton Solvation in Eleven Representative Liquid Media. Chem. - Eur. J. 17, 5808-5826 (2011). doi:10.1002/chem.201003164

29. Suu, A., Jalukse, L., Liigand, J., Kruve, A., Himmel, D., Krossing, I., Rosés, M., Leito, I.: Unified pH Values of Liquid Chromatography Mobile Phases. Anal. Chem. 87, 2623-2630 (2015). doi:10.1021/ac504692m

30. Buck, R., Rondinini, S., Covington, A., Baucke, F., Brett, C., Camoes, M., Milton, M., Mussini, T., Naumann, R., Pratt, K., Spitzer, P., Wilson, G.: Measurement of pH. Definition, standards, and procedures. Pure Appl. Chem. 74, 2169-2200 (2002). doi:10.1351/pac200274112169

31. Himmel, D., Goll, S.K., Leito, I., Krossing, I.: A Unified pH Scale for All Phases. Angew. Chem. Int. Ed. 49, 6885-6888 (2010). doi:10.1002/anie.201000252 
32. Mussini, T., Covington, A.K., Longhi, P., Rondinini, S.: Criteria for standardization of $\mathrm{pH}$ measurements in organic solvents and water + organic solvent mixtures of moderate to high permittivities. Pure Appl. Chem. 57, 865-876 (1985). doi:10.1351/pac198557060865

33. Gibson, S.C., Feigerle, C.S., Cook, K.D.: Fluorometric Measurement and Modeling of Droplet Temperature Changes in an Electrospray Plume. Anal. Chem. 86, 464-472 (2014). doi: $10.1021 / \mathrm{ac} 402364 \mathrm{~g}$

34. Bohren, C.F., Huffman, D.R.: Absorption and Scattering of Light by Small Particles. WileyVCH Verlag GmbH \& Co. KGaA, Weinheim (1998)

35. Van Berkel, G.J., Zhou, F., Aronson, J.T.: Changes in bulk solution $\mathrm{pH}$ caused by the inherent controlled-current electrolytic process of an electrospray ion source. Int. J. Mass Spectrom. Ion Process. 162, 55-67 (1997)

36. Mora, J.F. de la, Van Berkel, G.J., Enke, C.G., Cole, R.B., Martinez-Sanchez, M., Fenn, J.B.: Electrochemical processes in electrospray ionization mass spectrometry. J. Mass Spectrom. 35, 939-952 (2000)

37. Seo, J., Warnke, S., Gewinner, S., Schöllkopf, W., Bowers, M.T., Pagel, K., von Helden, G.: The impact of environment and resonance effects on the site of protonation of aminobenzoic acid derivatives. Phys Chem Chem Phys. 18, 25474-25482 (2016). doi:10.1039/C6CP04941A

38. Kebarle, P., Peschke, M.: On the mechanisms by which the charged droplets produced by electrospray lead to gas phase ions. Anal. Chim. Acta. 406, 11-35 (2000)

39. Peschke, M., Verkerk, U.H., Kebarle, P.: Features of the ESI mechanism that affect the observation of multiply charged noncovalent protein complexes and the determination of the association constant by the titration method. J. Am. Soc. Mass Spectrom. 15, 1424-1434 (2004)

40. Enke, C.G.: A predictive model for matrix and analyte effects in electrospray ionization of singly-charged ionic analytes. Anal. Chem. 69, 4885-4893 (1997) 